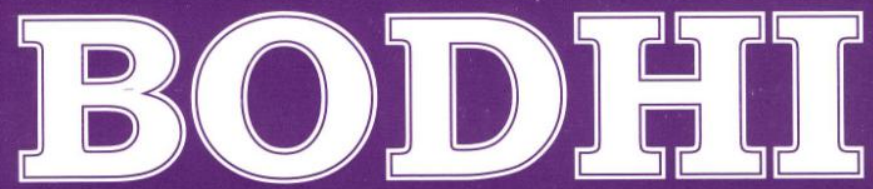

An Interdisciplinary Journal

ISSN: 2091-0479

Department of Languages and Mass Communication School of Arts

Kathmandu University

Bodhi, 4 (1), 111-135. ISSN 2091-0479. (C) 2010 Kathmandu University 


\section{Criticalizing the pedagogy of English studies: A Nepalese perspective}

- Ghanashyam Sharma

The educator confronts in its most hideous manifestation, power's vertiginous intoxication with the selective tradition of knowledge production in our schools. It is here that ... the non-Western thinker becomes the debased and inverted image of the hypercivilized metropolitan intellectually. . . . reason's Negative Other. -Peter McLaren, "Critical Pedagogy: Constructing an Arch of Social Dreaming and a Doorway to Hope"

\section{Introduction}

The globalization of the study of English literature began with the expansion of British Empire in the last two centuries, but the academic discipline now known as English Studies became global during and after the post-colonial second half of the twentieth century. In Nepal, a country that was never colonized, this discipline was voluntarily adopted from India, from where all of the models of secondary and higher education have been borrowed since the 1950s. At Tribhuvan University, the only public university and until the 1990s the only university system, English Studies has undergone radical transformation in its content and scope, especially in the last three decades. Its curriculum has metamorphosed from what used to be the study of canonical British literature (until the early 1980s), to the study of British and American literature (late 1980s), and then to the study of "literatures in English" along with literary theories including cultural and "non-Western" theories (since 1990s). However, in spite of the expansion in the content and scope of the discipline, no interest is evident towards integrating pedagogical theory and methods in the practice of English Studies. The lack of critical methods in teaching a "foreign" literatures and usually foreign critical apparatuses has 
kept the discipline what Freire (1994) calls banking of content upon students. Students make little sense out of studying English except to think of it as a means to get a certificate, job opportunities, and cultural capital. But the fact that the content and practice of English Studies have little relevance to the students' intellectual and social lives outside the act of getting a certificate and a job does not seem to bother the teachers and curriculum developers in the discipline.

Based on my teaching experience in Nepal, I argue in this article that the application of theories and methods of Critical Pedagogy would greatly enhance the relevance of the discipline, making it a more intellectually and socially useful practice of what Wallace and Ewald (2000) call "knowledgemaking" (p. 10) for the students and the Nepalese society at large. I discuss how the he integration of dialogue and active engagement of students in particular can make this discipline a better means for understanding other cultures and epistemologies of a globalized world without at the same time devaluing the knowledge of the local society, suppressing the knowledge-making agency of the learner, and the disregarding the social and professional needs that English Studies can and must fulfill. I propose the critical pedagogical means of dialogue and empowerment as two useful alternatives to the counterproductive traditional pedagogy of the discipline in Nepal. I define "dialog" not only a means of communication among participants of a conversation, like students and teacher in a class, but more broadly as a means of multilateral interaction among the learners, teacher, the cultures that the content represent or express, and the epistemologies of all those agencies involved in the pedagogical process. I also define "empowerment" more broadly than in the cliché of "knowledge as power": in the context of learning from foreign content and culture, the knowledge itself can be potentially disempowering if the pedagogy being used is uncritical. Finally, I also use the qualifier "critical" for "pedagogy" to suggest that learners should be conscious and engaged in thinking about the process as well as the content of learning. For example, banking the 
"critical" theories of Paul de Man can be as uncritical and "antidialogic" - to borrow Paulo Freire's term - as banking any other text or concept; the "critical" element of the content of a discipline makes little sense if the learner is not treated as an important epistemological agent in the process of education, as far as meaningful education is concerned.

The major benefit of using dialogue and empowerment in the teaching of English Studies in the non-native context of Nepal would be the creation of opportunity for students to become "knowledge-makers" rather than mere receivers of it. The use of these critical pedagogical approaches would shift the focus of teaching from having students merely learn about the literary, cultural, and philosophical discourses of foreign societies to engaging them in productive dialog with the bodies of knowledge from any societies and cultures in the world. As we all know, the discipline has already become the study of literatures and critical theories of any society in English; so the problem is not that the discipline is promoting a colonial mindset or anything of the sort, but it is the mindless banking of the great contents in uninspiring ways. The addition of "criticalized" learning process to the existing curricula would also help teachers and learners harness the positive potential of this discipline as a means for inter-cultural understanding. If a pedagogically critical model of teaching literature would help the teacher prevent the knowledge from dominating the individual learner and his or her local epistemology, culture, identity and consciousness, such a practice of the discipline would most importantly help the learner gain the skill of knowledge-making and take that skill into life and work beyond the classroom - instead of merely acquiring the knowledgecontent of the discipline as a final product.

\section{Dialogue as a means to critical learning}

As I indicated above, one of the most important tools of Critical Pedagogy that would make English Studies in Nepal a more pedagogically sound and productive practice is dialog. 
Discourses, like societies and cultures, are modes of communication; they are means of dialog among communities and cultures. But since the discourses of different communities and cultures are of unequal political/cultural capital, genuine educational practices should avoid the teaching of discourses of dominant cultures as dissemination of knowledge for its own sake, because doing so can reinforce existing power structures and patterns of domination among societies and cultures. In other words, when the cultural capital of powerful societies is taught uncritically and with no respect for less powerful ones, education will reinforce the status quo, perpetuating the unequal relationship among societies, especially in a globalized world. Instead, critical practice of academic disciplines like English Studies, which has a global reach and scope, can help us engage our students in a productive dialog with what they learn, thereby generating knowledge that really matters to them. The opportunity for critical dialog with the content of their learning will encourage students to use their own local knowledge and not just to passively receive the wisdom imparted by the great littérateurs and theorists of another culture. The integration of critical pedagogical approaches to the teaching of literature, and not just critical theories about literature, can help students understand their own positions as learners vis-à-vis the authority and authority of the societies that they learn from, or rather, interact with.

In his article "Critical Pedagogy and Intercultural Communication: Creating Discourses of Diversity, Equality, Common Goals and Rational-Moral Motivation," Shi-Xu (2001) proposes that

language and communication are a joint social activity that is embedded in broader cultural and historical, and by implication unequal power, context and . . . [so] current intercultural communication is itself part of the globalized competition ... unending local conflict and hostility, where social injustice and alienation are the order of the day. (p. 280) 
Only when we conceive of languages and literatures the means of dialog and understanding between cultures and epistemologies, can we begin to see how we can use those means to design day to day teaching learning activities in the classroom. In the context of Nepal, teaching English Studies, the idea of dialog is different from what it usually is in a native context. Let us take a scenario as an example: let us suppose that there are 150 students in a Nepali literature class in Kathmandu. In this situation, anyone can imagine that dialog would naturally mean discussing the literary and critical texts by explicitly connecting what the texts say to life, reality, and social and professional needs and challenges of the participants involved. Because of the students' familiarity with the knowledge- and culture- base of what they study, there will be a dialog between the student and the texts and contexts. But the moment we introduce foreign texts and contexts, say English, several complexities and challenges will automatically arise. First, in my experience, dialog among students usually stops and all heads turn towards the teacher ${ }^{1}$. Second, the students now feel powerless in front of all these great books written by great men in great societies out there ${ }^{2}$. Finally, as a consequence of the non-dialogic learning process that undermines the students' epistemological agency, students conceive of education as "knowledge," not learning: they will now be sitting there to "know" (about) things so they can get certain things done, including passing the exam, getting a job (with the help of a credential), or looking smarter in front of those who have less "English" knowledge. That is why critical pedagogical classroom practices will make a big difference. Dialog with the content can be a means for the learners to generate knowledge themselves, and in fact, a means for better understanding the context of the content as well.

\footnotetext{
${ }^{1}$ Also, in the current system, students come to class without having read anything - just because it is not necessary.

2 "Why don't we have such theorists and writers in our country?" said one of my students many years ago. I could never convince her that we do have theorists of our own.
} 
Critical pedagogical dialog can be multilateral: besides the dialog between students and the texts or cultures and epistemologies represented by the texts, there can also be a pedagogical dialog between students and teachers, and in fact a dialog with or about the learning process. The dialog with the learning process means asking: What am I learning, how am I learning, and why am I learning what and how I am learning? Only such a multilateral dialog between students and the other role-players involved in the learning process can make the discipline a genuine "contact zone" for knowledge-making. In my experience, the learning-dialog with the content learned is particularly important when the content is not directly related to or familiar for the learner.

Traditionally, English Studies in Nepal has only meant the teaching the "contents" of the "canon" (and often countercanon) of literature, linguistics, criticism, theory, and so on. But this pedagogy is rarely discussed, not to mention challenged. A brief reflection on some rough figures that I can remember might explain the pedagogical failure I am hinting at. At the central department of English in TU (which enrolls almost 90\% of all the English major students in the country), when only a small fragment of the 1500 MA-English students "pass" with the $40 \%$ score, the blame goes to the student; the problems with the pedagogy are rarely considered seriously. When the historical record score was, until recently, less than $80 \%$ and only a few students scored above $60 \%$ every year, students automatically blame the system of evaluation which is said to start from ground zero: they too do not see the problematic worldview about education that underlies the failure of the system. Very few administrators are ready to address the pedagogical basis of this tragic situation. It is hard for most teachers of English Studies to see how a wrongly delivered education has been insulting generations after generations of youths most of whom end up in the humiliation of being defined by a percentage score rather than by an engagement in learning, because nothing they know will ever count as knowledge; their learning and life will never be as valuable as 
understanding Derrida, sitting among a hundred people in a classroom where they can barely hear the teacher-not to mention getting a chance to share and create new knowledge through productive dialog with the teacher and fellow students. This brings us to the question of practical difficulties of implementing critical pedagogy, but I will address this challenge in a separate section later on.

Teaching canonical literature with only the critical apparatus of critical theory is not sufficient because only critical pedagogical approaches that involve the learner as an active agent in the dialog with the body of knowledge is what is necessary to address the above situation. Teaching critical content should not be confused with the real need: critical teaching and learning. With only critical theory to interpret literature, students will still use someone else's spades to till someone else's fields. Proficiency in the knowledge of English literature and accompanying critical theory will inform a Nepalese student about Anglo-American (and some other cultures), but just "getting" that information/knowledge about those societies and cultures (in the form of literature and theories) very often makes little sense in their life and work. Not only teaching critical theories but even teaching theories "about" dialog or learning can be called banking. What is needed is critical pedagogical methods translated into classroom practice: "A discursive transformation," argues Shi-Xu (2001), "can be accomplished, not by some external decree, but through an internal, teacherstudent, theorist-practitioner dialog which initiates, (re)formulates, motivates and practices those discourses" (280). Critical pedagogical practices of dialog learning can be developed by drawing from the tremendous body of knowledge in various fields of educational practices in the world. Shi-Xu, shows how

bringing in/about ... pedagogical, discursive changes involves methodological issues: [that is] how to introduce and implement changes? These issues may be seen and tackled at three levels of pedagogical practices .... a the textual level .... at the interactional level, [where] 
teachers ... should try to establish and follow new and alternative rules of pedagogical interaction or discourse .... [in the] society as a whole." (p. 288)

As a result of an "antidialogic" pedagogy of English Studies in Nepalese universities, such a useful discipline has been in many ways a tool of what Freire calls "cultural invasion" of the West. Discussing such an anti-dialogical academic culture, Paulo Freire's ideas from his famous Pedagogy of the Oppressed come to mind. Freire (1994) says that

antidialogical action has [the] fundamental characteristic: cultural invasion, which like divisive tactics and manipulation also serves the ends of conquest. In this phenomenon, the invaders perpetrate the cultural context of another group, in disrespect of the latter's potentialities; they impose their own view of the world upon those they invade and inhibit the creativity of the invaded by curbing their expression. (p. 133)

Paradoxically, there are no human invaders involved, just the content. But that is why the idea of dialog with knowledge becomes relevant.

Due to the excessive attention to the content of the discipline, all other problems and weaknesses of the pedagogy seem to go unnoticed or actively ignored. Referring to the need of Freirean critical consciousness in the classroom, Bizzell (1992) says in her article "Academic Discourse and Critical Consciousness":

Often, to go through college is to be indoctrinated, or as Freire would have it, passively filled with the contents of disciplines. This oppressive kind of knowing is fostered by the attitude that disciplinary content matches or mirrors reality, or to put it another way, that disciplinary content is empirically true. If there were the case, there would be no need for 'searching,' 'invention' and 'invention and reinvention. (p. 137) 
In the non-native context of English Studies in Nepal, that attitude about content as king results in more oppressive pedagogical practices. Many teachers of the discipline are uncritically convinced that since the great tradition of literature, the canon, is what matters, there is not much space for critical dialog with the body of that knowledge. Even when critical dialog about the cultural politics of the canon enters the classroom, the learner does not become an active epistemological agency in the typical literature classroom. Perhaps the assumption is that after all the student of literature is there to learn from greatest creative writers and philosophers of all times, and not to create knowledge themselves. Thus, the use of a more dialog pedagogical practice of the discipline can help us achieve one of the most important potentials of a global discipline like English Studies - knowledge-making, as well as knowledge-getting.

\section{Pedagogy and em(power)ment: Epistemological hegemony vs. liberatory education}

The concept of dialog and entails the need to share power. The alleviation of domination of the learner by the content of knowledge learned as well as the process of learning it means that the decentering of power in the classroom, not just from teacher to students but also from the content and the way it is practiced towards promoting the students' knowledge-making agency. Power and domination take concrete forms when the learner cannot question some imposed knowledge, cannot put that knowledge into practical use, or cannot relate it to his or her own local context of life and knowledge because knowledge that comes in the form of "great" literature, philosophy, or theory can be easily seen as the truth that can only be pronounced by "authorities" (or authors). Such knowledge, especially when it does not come from the learner's own society or culture can take the form of cultural, political and economic domination and the process of such education can alienate the 
learner from the bases of his or her own culture, society, and work. It is true that in the case of English Studies, higher education in the discipline usually brings about tremendous social and economic benefits. And yet, even when such knowledge does bring about socio-economic benefits, it can damage the culture and identity of the learner and in the long run. This is important if we consider that the domination of the learner by what we call "knowledge" as contrary to the concept of "education as liberation."

The domination of the learner by the knowledge learned can be avoided if the process of learner is designed not just to "get" the knowledge but to empower the learner to question as well as acquire knowledge, generate as well as receive knowledge, and use as well as accumulate knowledge. In other words, since the content of English is usually texts produced in culturally powerful/dominating as well as economically advanced Western societies, a simple transmission — or banking — of such knowledge will perpetuate what J. Elspeth Stuckey calls the "violence of literacy." The violence would work like a doubleedged arrow: on the one side, the uncritically imposed cultural capital of literature and theory will convince the learner from dominant societies about the supremacy of that culture, and on the other side it will turn the learner of other societies into selfdestructive tools of perpetual hegemony. In particular, if the learners fail to see themselves as potential knowledge-makers in relation to the knowledge they receive, their learning will initiate or magnify the erosion of local knowledge, consciousness, and value of the many less powerful societies/cultures of the world.

In their article "The Globalization of Capitalism and the New Imperialism: Notes Towards a Revolutionary Critical Pedagogy," Farahmandpur and McLaren (2001) argue that "[e]ducation is involved in the direct production of the one commodity that generates the entire social universe of capital in all of its dynamic and multiform existence-labor capital" (p. 297). Now, in a world where the non-native students of English 
who outnumber the native are to become the "negative other," and more unfortunately without being conscious of that, why should they participate in this self-humiliating pursuit? The answer to this complex question lies not in escape but in what McLaren calls the "arch of social dreaming" and our capacity to construct that arch through a more conscious and critical engagement with the discipline. The idea of "dreaming" implies that a critical pedagogue cultivates hope and determination; and the idea of the "social" implies that pedagogical practices must relate to real life and society where that practice is based.

In another article titled "Revolutionary Pedagogy in PostRevolutionary Times," McLaren (1998) adds: "Critical Pedagogy is a way of thinking about, negotiating, and transforming the relationship among classroom teaching, the production of knowledge, the institutional structures of school, and the social and material relations of the wider community, society, and nation-state" (p. 441). McLaren believes that Critical Pedagogy is capable of making educational pursuits overcome the oppressiveness of "ethnocentric tendencies of modern, Western grand theories that teleologically privilege certain historical or philosophical endpoints to the human condition" going to the extent of "sound[ing] the death knell of political agency such as "the death of the subject"' (p. 454). This promise - or potential-of Critical Pedagogy is a significant hope to me as a teacher of English who has been painfully conscious that the great literature high theory of the West is culturally oppressive of the non-Western student.

To extend the idea of solutions, Ibrahim (2007), in his eclectic observation of the function of critical pedagogy, "Linking Marxism, Globalization, and Citizenship Education: Toward a Comparative and Critical Pedagogy Post 9/11," surveys the literature on what he calls "education sans frontieres" and prompts us to ask the question as to how Critical Pedagogy could help us transcend the cultural and political limits as educators. By reviewing three recent works by Critical Pedagogy scholars, Ibrahim suggests that this is a hope worth 
cultivating and striving for as educators in a world where conflict and misunderstanding are not decreasing. Indeed, "dreaming" to overcome the hegemonic structures, and translating those dreams into actual pedagogical practices to the extent we can, would help us as English teachers and students to deal with the potentially disempowering element of the discipline. Theories of Critical Pedagogy that expose the cultural and capitalistic politics of literature and theory would fulfill a serious lacuna in the study and practice of English in Nepal.

It is obvious that English students' motivation to study this discipline is largely economic and that they will become a tool of propagating that same capitalistic order by participating in the commodification of "English." If that is the case, it is imperative that students and teachers be aware of their potential complicity in reinforcing an oppressive global order by using a cultural discourse as an exploitative economic tool. The "critical" function of Critical Pedagogy that exposes not just the abstract injustice inherent in the content of the English discipline but the injustice in the lived experience of the learner can keep the praxis of this discipline from being the praxis of social, cultural, and intellectual oppression. It can make the discipline promote the potentially limitless opportunities to understand the world.

\section{Resistance, not rejection: Finding solutions}

As I have been suggesting above, the resistance to cultural hegemony should not close the door to the actual goal of engaging in an inter-cultural dialog through the medium of a global discipline like English Studies, and the door to empowerment of the learning through dialogic learning. Of course, curricular practice is undeniably cultural and political, and only dogma or servility can keep us from being conscious that teaching the language or literature of another culture will be an imposition of a problematic cultural capital. At the same time, however, resistance and rejection of trans-cultural and 
trans-national discourses-be it English Studies or the increasing popularity of another language or technology-will only yield loss in the process of a necessary dialog and learning from different cultures.

In the context of Nepal, since the content of a discipline comes from other socio-cultural worlds, there is always the risk of that content oppressing the local knowledge that the learner brings into the learning process. But this is not a reason to avoid learning from others; it is instead a reason to find out ways to avoid the oppression of the learner, or ways to make the learning more relevant and productive. In Curriculum as Cultural Practice: Postcolonial Imaginations, MacPherson (2006) proposes a constructive model for teaching English that will help us avoid "stealing" the languages and cultures of nonEnglish speaking learners. Although MacPherson's context is that of teaching the English language to foreign students, I find his ideas of inter-cultural dialog relevant to the context of teaching English Studies as well because they can be productively adapted and applied for significant results in contexts like Nepal.

MacPherson's critical considerations of both the dangers and the benefits of a global language and discourse is worth elaborating here. In the face of rapid globalization, which MacPherson calls the "collapse of space and time," it is easy for the western learner to "see what is local and relative as universal" (p. 75). When the failing to see the western local as global is combined with power and coercion, the result can be the perpetration of "great harm in the name of good. Neither outright resistance nor smug assimilationism will do justice to the marginalized peoples and cultures of the world. MacPherson proposes a solution: "A genuine postcolonial resolution is to negotiate a way for humanity to move beyond the sense of a narrow choice between extremes of monocultural assimilation and fundamentalism" (p. 78). That will constitute an "international, intercultural Third Space" towards a better understanding of world communities through what he calls the 
"presence of choice" (p. 79) to learn from each other. MacPherson proposes that we do not "STEAL (Surreptitiously Teach English as an Assimilationist Language) (p. 79)" but "TELL (Teach English as a Liberatory Language) (p. 86)."

The idea of "stealing" or "telling" applies very well in the context of teaching literature as well. If English language is taught with the aim of forcing learners of other cultures to assimilate into the English speaking culture, as MacPherson (2006) suggests, the spread of English as a global language will bring about "cataclysmic erosion or outright elimination of human diversity in languages, cultures, and consciousnesses" and this is what is happening to a great extent in the world. So is the case with imposing British-American literature as the "standard" of English literature because "English" Studies as a global discipline has clearly transcended the study of canonical literature of England (and then of British and America) into becoming a field of study of literatures, critical theories, and even cultures and philosophies of the world in the common medium of the English language. The claim that English language - and "standard" English at that-is the means of English literature (and now critical theory) within the English department/ discipline is a poor justification to favor the literature or theory constructed in English speaking cultures if we want to claim the status of a global discourse for this discipline. The relocating of the learner as an agent of knowledge-making through a critical dialog with the content of learning and critical pedagogical approaches for empowerment will help us see that the learner's local bodies of knowledge can and should become legitimate issues of discussion in the medium of the discipline of English Studies. That is where the need for a critical, knowledge-making dialogic engagement of the learner becomes as important as the issue of content in this discipline.

Thus, to the question whether the risk and danger of the assimilationist imposition of English language or literature 
justify a fundamental resistance of it, I say, No. I would like to cite MacPherson (2006) again:

Yet, these are the questions that we need to suffer to hold in our awareness without wincing, without fighting or swooning in the dubious bliss of ignorance. The response we do not want to make is to bury our heads in the sand with the hopes that the questions will go away or prove mistaken. (p. 81)

There is the constructive side to the potentially dangerous path of this knowledge. Those who resist help create a richer body of knowledge compared to those who acquiescently adopt a given body of knowledge. If we criticalize English Studies with the means of dialog and empowerment of the learner, we would be able to realize the potential function of English Studies as a global discipline towards making it a "conduit to the 'global,' transnational network of education, justice, economic development, and mobility ... [or] what liberation means to most people in the world" (MacPherson, p. 86). As a teacher of Tibetan refugees in India, the author speaks from direct experience of how disenfranchised people are able to join, with the medium of English, into the "transnational community of people who support their political, activist, religious, ecological, and economic aspiration and needs."

A more critically conscious pedagogy of English Studies would enhance the struggle of people of different cultures and contexts to understand one another. Properly done, English Studies could be a platform for intercultural understanding.

\section{The question of practicability}

The concepts of negotiation and power-sharing with (or the empowerment of) the learner are almost unheard of in the traditional pedagogy of English Studies in Nepal. Theories of the power of discourse or cultures, like Foucault's, are taught considerably frequently but they seldom get as close as pedagogical concerns, not to mention the power involved in 
classroom dynamics. Theories of power are bandied about; contexts and cultures are discussed; the political, cultural and such other functions of "knowledge" are endlessly theorized; but little is heard about how and why to "learn" that knowledge, about how to teach and practice it. The learners' place in that process of learning (or is it just "knowledge"?) and the value of that knowledge in their lives might only be tangentially touched upon in the abstract, if at all, in literary theory. Because English Studies is a discipline where significant power is exercised in the learning process in the form of power of texts and their canon, and through cultural hegemony that those texts bring about, the pedagogy of this discipline undoubtedly need to develop rigorous strategies for empowering students in the teaching-learning process. As of now, such a need for a more dialogic and empowering pedagogy is basically dismissed because of practical difficulties and the nature of the discipline itself.

One of the excuses made by English teachers for just teaching the texts and not taking seriously enough pedagogical concerns like the need to empower students in the learning process or even to engage them in dialog in the classroom is that this is a discipline comes with a natural focus on content. My contention is that teachers who point to the supposed "nature of the discipline" are using such a lame excuse to justify their own lack of readiness to change the pedagogy: to say that content is king in English Studies is to justify intellectual laziness and pedagogical irresponsibility. In fact, the resistance or lack or readiness to change the pedagogy of the discipline is based on several untenable assumptions. One assumption is that the content of (great) literature and theory is "out there" to be learned. The problem with such an assumption is that it comes at the cost of the respect for the learner's need to make sense of the body of knowledge. Moreover, especially when the content of English Studies is foreign to the learner's experience, culture, values, and identity, this assumption also becomes almost ludicrous and against the genuine reason of learning from other societies and cultures. It is tantamount to making an 
absurd prescription for practicing parrot-learning at the university level.

Another excuse for downplaying the need for critical models and pedagogical practices for teaching of the discipline comes from the fact since students of literature are not there in the class to produce anything themselves - like they are in a writing class-but to consume knowledge. From a semester-long archival study of the teaching of writing at the beginning of the twentieth century at the University of Louisville, I was convinced that there was a time when writing was also conceived as learning to (re)produce good models by good writers through imitating them. As far as I understand, it was the introduction of more critical pedagogical methods of teaching that redefined writing as "composition" of knowledge by the learner and the sources (authors and texts) became only accessories in that process.

Yet another excuse is that literature classes are not designed (in size, resources, or in other ways) so teachers will be able to engage individual learner in the same kind of knowledgemaking as in a composition class. My reaction to that assumption is simpler: why don't we redesign it then? In the case of developing countries with limited resources too, the response to that question is the same: whatever is possible in a writing class will be possible in a literature class-given the teacher or the tradition of teaching has the will to do it similarly.

From my teaching experience of English Studies in Nepal, I am convinced that the problem behind practical "difficulties" is the scholars' and teachers' apathy towards the importance of pedagogical methods for the practice of that education. As I indicated above, it would seem that the non-use of critical pedagogical approaches in the teaching of literature in large classes, with as many as a hundred students per classroom, is a matter of circumstance, or obligation, and not choice. But if we consider that there is a similar lack of interest in making 
classrooms student-centered and learning relevant to the local society even in situations where it would be possible to update the traditional "banking" of content would be quite possible, we are bound to think that that is considerably a matter of refusal to pay as much attention to the learning process as to the content for learning (or teaching). Let me add another practical example here. There are similar numbers of students per class in the Departments English Education as there are in the Department of English/Humanities at Tribhuvan University of Nepal, where, let us consider, a similar course in linguistics is taught as the foundation for teaching English and the foundation of literary studies respectively. The courses could be taught in the same way, considering that they are foundation courses where course goals are similar; but in reality, students in the education classes learn through classroom interaction and a host of other dialogic pedagogical practices, whereas students in the humanities classes never engage in anything but listening to lectures and taking notes. The physical circumstances are identical, the pedagogical cultures different. While the same traditional tendencies of banking are also found in the Education Department, English Studies in the Humanities is stunningly "banking," relatively speaking.

The laying of blame on practical difficulties, the nature of the discipline, and so on is, however, not unique to Nepal: it seems to be a colonial legacy inherent in the very discipline. Here is a brief observation of that lack of concern for pedagogical rigor in English Studies even in the United States. In her essay "Contact Zone and English Studies," Bizzell (1994) states:

Our Ptolemaic system of literary categories goes creaking and groaning onward, in spite of the widely acknowledged need to overhaul it in response to multiculturalism. This is not to say that there have not been attempts to revise course design in light of new materials and methods ... . But [the] attempts to foster innovation in the individual classroom still leave the basic structure of English studies intact. (p. 63) 
As Bizzell suggests, a "radically new system is needed to organize English Studies"- even in the United States-in the direction that only a few writers and teachers have recently tried to "address the pedagogical consequences of deconstruction, feminist literary theory, and cultural studies .... and also incorporate more diverse literatures" (p. 163; emphasis mine). As Bizzell suggests, even the few radical "attempts to foster innovation in the individual classroom still leave the basic structure of English Studies intact." It is necessary to overcome the old belief in the "underlying structure of English Studies that still makes us think our scholarship must be organized along national or chronological lines".

There seem to have been attempts towards incorporating pedagogical methods in the English Literature classroom. Bizzell mentions a few of them ${ }^{3}$ and discusses two recent attempts towards restructuring English Studies in more detail: MLA's publication of Stephen Greenblatt and Giles Gunn's Redrawing the Boundaries: The Transformation of English and American Literary Studies (1992) "with the avowed intention of fostering innovation," and "another recent attempt to chart new courses, the MLA's 1987 English Coalition Conference" (p. 164). She says that the focus of the latter, at least, is "clearly on pedagogy rather than on the body of scholarly knowledge"; but this too has "very little to do specifically with the discipline of English Studies." Suggesting that much more needs to be done, she says that developing

a new system of organization from the new materials of study ... . would seem to require that we make generalizations about the new material-about what, say, might be required to study Asian-American literature adequately - that would be extremely difficult, if not downright presumptuous, to make. I think we need an approach to the diverse world

\footnotetext{
${ }^{3}$ G. Douglas Atkins and Michael L. Johnson's Writing and Reading Differently (1985), Susan L. Gabriel and Isaiah Smithson's Gender in the Classroom (1990), and James A. Berlin and Michael J. Vivion's Cultural Studies in the English Classroom (1992). Discussing
} 
literatures written in English we are now studying that focuses not on their essential nature, whatever that may be, but rather on how they might, not "fit" together exactly, but come into productive dialogue with one another. (p. 165)

Bizzell also presents a specific solution: "I suggest that we address this problem by employing Mary Louise Pratt's concept of the "contact zone." "She quotes Pratt:

I use this term to refer to social spaces where cultures meet, clash, and grapple with each other, often in contexts of highly asymmetrical relations of power, such as colonialism, slavery, or their aftermaths as they are lived out in many parts of the world today.

(p. 165)

Bizzell argues that if we understand that we are teaching in, and about, contact zones, as Pratt suggested "we must stop imagining our job to be transmitting a unitary literature and literacy" (qtd. in Bizzell 166). Such a pedagogical approach would include "provid[ing] a rationale for integrating English Studies multiculturally," "fully integrat[ing] composition and rhetoric into literary studies," and "giving a dynamic new direction to our profession".

Bizzell's practical solution to the challenge of how we can teach literatures of diverse world cultures written in English is practically relevant for the context of teaching English Studies in Nepal. Such a project could be furthered by drawing from the many pedagogical models found in the discipline of Critical Pedagogy.

\section{Developing practical practices}

Discussions about and some efforts towards implementing critical pedagogical methods and models in the teaching of English Studies have only recently begun in the South Asian region. A teacher of English Studies who specializes in the application of Critical Pedagogy in the teaching of English literature in North-Eastern University of Shillong, India, author 
Kailash C. Baral, in his article "Postcoloniality, critical pedagogy, and English Studies in India," illustrates how Critical Pedagogy can resolve the double bind between practicing a discipline that imports hegemony and rejecting the opportunity of learning about other cultures of the world: "To ensure a desired social change, Critical Pedagogy is relevant in both its liberating and strategic dimensions" (484). Baral cites Antonia Darder: "Unlike traditional perspectives of education that claim to be neutral and apolitical, Critical Pedagogy views all educational theory as intimately linked to ideologies shaped by power, politics, history, and culture" (ibid). Such discussion of the political nature of pedagogy is a new phenomenon in the region.

Let me add some details about the political and cultural background where Baral (2006) advocates the integration of Critical Pedagogy into the discipline of English Studies. According to him, the Indian academe has a "complex relationship with the legacy of English both as a language and as a literary discipline .... [because it is] a product of both colonialism and postcoloniality, [and] is also entwined with the global status of English today in the wake of technological revolution" (p. 475). English as a language has changed from being a "symbol of imperialism and identified with a certain class or caste of people" into "the language of opportunity .... as a language of communication and creative expression ... as a disciplinary study .... as a symbol of people's aspiration of quality education ... and a fuller participation in national and international life" (p. 476). But it is precisely because of this growing importance and more diverse roles of English that its practice needs serious pedagogical attention. Baral says, "the location of English Studies within a postcolonial curricular structure today has intensified the debate on its sociohistorical and cultural implications .... [and it is necessary to] to examine the curricular politics and pedagogical issues of English in India in the context of English Studies as a discipline" (p. 477). Unlike many other postcolonial scholars, Baral does not reject the practice of English as a political/hegemonic episteme 
imposed upon a once colonial society. Instead he sees this global discipline as being capable of empowering marginalized groups of people in his society; as a teacher he is rather convinced that the situation "demands a serious look at the discipline of English Studies in the context of its content, institutional politics, and, most importantly, its pedagogical practices" (p. 479). This is where the English -teacher-astheorist becomes a responsible practitioner of a socially - even globally - significant episteme.

A further dimension in Baral's demonstration of the need for aligning Critical Pedagogy with English Studies is that of its "pedagogical practice as freedom" as well as a pragmatic discipline that brings about economic and cultural opportunities, because "[s]uch an imperative is implicated in the very object of education to give voice to the voiceless, enfranchise the marginalized .... [through the] pedagogical strategy ... of dialog as a necessary condition of learning in a world of multiple conversations" (p. 482). Citing Lalita Pandit and Jerry McGuire, Baral on the one hand acknowledges that that we can not develop any global models of pedagogy: "They take note of the failure of the global models, global aspirations, global assumptions." But at the same time, he suggests that a humanistic awareness is both possible and necessary in the practice of English Studies as a "core area of humanities": "[t]he curriculum that we prescribe for our learners needs to be simultaneously pragmatic and open to global aesthetics within a humanistic perspective" (pp. 485-86). The traditional function of English literature as "aesthetic pleasure" and its function of "prophecy" that privileges the Western cultural world view and civilizational values over the non-Western learner's own, Baral suggests, are no longer the issue: "Operating under the props of necessity and power, English Studies has to recognize the intellectual forces that have shaped our present, and the forces in turn will provide a critical context for an appropriate pedagogy for its study" (pp. 483-84). 
I find Baral's model that makes room for both the Utopian function of Freirean pedagogy and the pragmatic function of English as a global language and discourse highly pragmatic; unlike the knee-jerking position of some postcolonial critics of English study as Western hegemony or the position of some English pundits for whom Greco-Roman-Anglo-American history of knowledge is "the" history of knowledge, such a position of openness to learning and questioning at the same time is useful and meaningful.

I will conclude with another image, this time an imagined one. With the next radical transformation of the discipline - this time pedagogical - in a few years to come, I imagine the Nepalese English teacher moving to the back of the classroom (Shor's "Siberia") after only a ten minutes lecture, instead of speaking every minute of the class as she has always done; I imagine the students discussing what sense the ideas of a Donne or a Derrida makes to their own life and work, instead of only busily taking notes to pass the exam. I imagine the Nepalese student of English writing a paper (which he has never done before) that the teacher (en) trusts his peer to take home and review. I understand that the teacher will not be able to read weekly papers written by 150 students in her class; but I believe in the power of the teacher's imagination and readiness to reconfigure how she or he teaches. I believe that criticalizing the pedagogy of English Studies in this country can help us in "constructing [the] arch of social dreaming and a doorway to hope" as I cited McLaren in the epigraph. A pedagogically sound practice of this global discourse has the power to transform the society. But first we must be ready to transform our practice of it.

\section{References}

Baral, K. C. (2006). Postcoloniality, critical pedagogy, and English studies in India. Pedagogy: Critical Approaches to Literature, Language, Composition, and Culture, 6 (3), 473-91. 
Bizzell, P. (1992). Academic discourse and critical consciousness. Pittsburgh: University of Pittsburgh.

Bizzell, P. (1994). Contact zones' and English studies. College English, 56 (2), 163-69.

Farahmandpur, R., and McLaren, P. (2001). The globalization of capitalism and the new imperialism: Notes towards a revolutionary critical pedagogy. Review of Education, Pedagogy \& Cultural Studies, 23 (3), 271-315.

Freire, P. (1994). Pedagogy of the oppressed (20 $\mathrm{th}_{\mathrm{t}}$ anniversary ed.). NY: Continuum.

Ibrahim, A. (2007). Linking Marxism, globalization, and citizenship education: Toward a comparative and critical pedagogy Post 9/11. Educational Theory, 57 (1), 89-103.

MacPherson, S. (2006). To steal or to tell: Teaching English in the global era. In Y. Kanu (Ed.), Curriculum as cultural practice: Postcolonial imaginations. Toronto: University of Toronto.

McLaren, P. (1991). Critical pedagogy: Constructing an arch of social dreaming and a doorway to hope. Journal of Education, 173 (1), 9-34.

McLaren, P. (1998). Revolutionary pedagogy in postrevolutionary times: Rethinking the political economy of critical education. Educational Theory 48 (4), 431-62.

Shi-Xu. (2001). Critical pedagogy and intercultural communication: Creating discourses of diversity, equality, common goals and rational-moral motivation. Journal of Intercultural Studies, 22 (3), 280-93.

Mr. Sharma is pursuing doctoral studies at the University of Louisville in Louisville, Kentucky, USA. 